This document is the accepted manuscript version of the following article:

Casas-Mulet, R., Vanzo, D., Adeva-Bustos, A., Macnaughton, C. J., Stewardson, M. J., Pasternack, G. B., ... Dyer, F. (2020). How to strengthen interdisciplinarity in ecohydraulics? Outcomes from ISE 2018. Journal of Ecohydraulics.

https://doi .org/10.1080/24705357.2020.1813057

\title{
1 How to strengthen Interdisciplinarity in Ecohydraulics? 2 Outcomes from ISE 2018
}

4 Casas-Mulet $\mathrm{R}^{1,2, \S}$, Vanzo $\mathrm{D}^{3}$, Adeva-Bustos $\mathrm{A}^{4}$, Macnaughton $\mathrm{C} \mathrm{J}^{5}$, Stewardson $\mathrm{M} \mathrm{J}^{2}$, 5 Pasternack $\mathrm{G} \mathrm{B}^{6}$,Enders $\mathrm{E} \mathrm{C}^{7}$, Dyer $\mathrm{F}^{8}$

${ }^{1}$ Aquatic Systems Biology Unit, School of Life Sciences Weihenstephan, Technical University of Munich, 85354 Freising, Germany

${ }^{2}$ Department of Infrastructure Engineering, School of Engineering, The University of Melbourne, 3010 Parkville, Victoria, Australia

${ }^{3}$ Surface Waters - Research and Management, Eawag - Swiss Federal Institute of Aquatic Science and Technology, Kastanienbaum, Switzerland

${ }^{4}$ Department of Energy Systems, SINTEF Energy Research, 7034 Trondheim, Norway

${ }^{5}$ Independent Researcher (Aquatic biology), Montreal, Canada

${ }^{6}$ Departmetn of Land, Air and Water Resources, University of California, Davis, United States

${ }^{7}$ Freshwater Institute, Fisheries and Oceans Canada, Winnipeg, MB, Canada

${ }^{8}$ Centre for Applied Water Science, University of Canberra, Canberra, Australia

${ }^{\S}$ corresponding author: roser.casas-mulet@tum.de 


\section{Abstract}

34 Interdisciplinary approaches are needed to tackle complex environmental issues as freshwater

35 ecosystems face unprecedented pressures globally. The emerging Ecohydraulics field of research

36 should take steps towards developing true interdisciplinarity and embrace the transformation

37 required as the world keeps changing in front of our eyes. This paper aims to contribute to the

38 discussion on interdisciplinarity in Ecohydraulics and to shape its growth. This contribution builds upon

39 previous research that identified the challenges and opportunities for early career researchers (ECRs)

40 in Ecohydraulics and takes a step further on identifying key actions, actors, and implementation

41 strategies that can strengthen interdisciplinarity. Based on an online questionnaire and a workshop

42 involving over 150 early and established careers, we present a list of 20 prioritised actions that will

43 help engage the research community towards specific goals and will result in increased

44 interdisciplinary outcomes. While ECRs have taken the lead on creating this roadmap, its

45 implementation should be a joint responsibility of both ECRs, established career scientists, groups,

46 and institutions within Ecohydraulics. The list of identified actions and assigned responsibility should,

47 therefore, be considered a conversation starter among the Ecohydraulics community on how to

48 strengthen interdisciplinarity. This means that a continued revision of the here stated approaches will

49 be required to in the future, as the field of research and its community progresses. With this

50 contribution, we resume a critical reflection on where the Ecohydraulics field of research and

51 community stands today and where efforts need to be invested in the long-term to consolidate its

52 inherent interdisciplinarity.

53

54

55

56

57 
Interdisciplinary approaches in science are essential to understanding the complex challenges brought by current global environmental changes. This is why interdisciplinary research has been well recognised by funding and government agencies for decades (e.g. Engineering Committee on Science, 2004; European Research Advisory Board, 2008). However, fostering effective interdisciplinarity faces many barriers, starting with a lack of common understanding of the factors that make interdisciplinarity work (Huutoniemi et al., 2010; Kumar et al., 2019; Schummer, 2004) which hinders its implementation. Despite having a central role in science policy debates and funding schemes, interdisciplinary research still appears to be poorly rewarded in terms of recognition and careerbuilding (Bina, 2017). For individuals from different disciplines to work together and maximise the benefits for the scientific community, these barriers first have to be resolved (Freeth and Caniglia, 2020; Hicks et al., 2010). In this context, research teams in the scientific community need to continuously improve their interdisciplinary toolkit, drawing on hands-on experiences (e.g. learn to collaborate while collaborating, Freeth and Caniglia, 2020), and investing in identifying inclusive, bottom-up or peer-driven strategies for effective interdisciplinarity.

As an interdisciplinary field of research, Ecohydraulics faces the same pressures and challenges of interdisciplinarity. Indeed, anthropogenic pressures threatening freshwater ecosystems worldwide (Döll and Zhang, 2010; Vörösmarty et al., 2010), and the increasing awareness of their importance for global conservation efforts (Geist, 2011; Reid et al., 2019; Strayer and Dudgeon, 2010) have led to an emergence of integrative fields of research such as Ecohydraulics. Ecohydraulics combines core disciplines of hydrology, fluvial geomorphology, engineering, and ecology (Maddock et al., 2013a) to understand physical and ecological processes in rivers at a range of scales (Gosselin et al., 2019; Pasternack, 2019). While disciplines within Ecohydraulics interact at different multi-, inter- and transdisciplinary levels (see Casas-Mulet et al., 2016), here we adopt the more inclusive definition of interdisciplinarity by Hicks et al. (2010): 'the production of research which crosses disciplinary boundaries', and is considered to cover all three levels of disciplinary interaction. As such, interdisciplinarity in Ecohydraulics is what gives it the potential to play a crucial role in the future management of freshwater ecosystems (Maddock et al., 2013c, 2013b; Nestler et al., 2016; Rice et al., 2010).

A crucial achievement in promoting interdisciplinarity has undoubtedly been the foundation of the Journal of Ecohydraulics (TJoE, Kemp and Katopodis, 2016), which highlights Ecohydraulics research, as well as providing a platform for the integration of non-engineering disciplines (e.g. Hannah et al., 
2007; Lancaster, 2018). Despite the advances, Ecohydraulics has not yet reached the necessary level of integration for true interdisciplinarity. A study on the last twenty years of Ecohydraulics conference proceedings suggests a potential stagnation phase in interdisciplinary research (Casas-Mulet et al., 2016). The study found only a small detectable increase in interdisciplinarity activity between neighbouring research areas (e.g. physical habitat and flow responses), and no growth among more distant topics (e.g. hydraulic modelling and biotic responses, or social aspects) during the investigated period. In contrast, the need to solve water management problems has engaged Ecohydraulics research with end-users from its inception and has a been a key driver promoting the development of Ecohydraulics as a distinct field of applied research (Nestler et al., 2008).

There is a need for a wider acceptance of Ecohydraulics as a whole discipline with both a basic science foundation (Nestler et al., 2016; Pasternack, 2019) and a critical impact on society that emerges when addressing research questions beyond traditional subject boundaries and scales. Stronger interdisciplinary collaboration and cooperation among researchers, end-users, and managers are considered necessary to achieve this goal (Dollar et al., 2007; Rice et al., 2010). A bi-directional stimulation is needed. On the one hand, a relevant challenge appears to be the implementation of interdisciplinary research into actions on the ground (Casas-Mulet et al., 2016), both at the scientific and societal levels. On the other hand, practitioners can play a central role in steering Ecohydraulics fundamental research and should challenge scientists to improve and further basic science (Palmer et al., 2010).

In order to contribute to society on local and global scales, Ecohydraulics needs to support the new generations of freshwater scientists (Wilkes et al., 2016). Early career researchers (ECRs) face additional challenges as they need to build their careers in a way that crosses traditional disciplinary boundaries, integrating physical, ecological, and social values in Ecohydraulics. To date, the efforts of

113 the Early Career on Ecohydraulics Network (ECoENet) have been to promote inclusivity and open114 mindedness among emerging researchers and encourage their participation in the scientific 115 community. However, more work is needed to engage emerging researchers in the consolidation process of interdisciplinarity in Ecohydraulics.

117 By taking both an ECR and established academic perspective, this paper aims to contribute to the 118 discussion on interdisciplinarity in Ecohydraulics and to shape its growth both among the community 119 and the field of research. This contribution builds upon previous research that collected the challenges and opportunities for ECRs in Ecohydraulics (Wilkes et al., 2016). From this, we identified key actions, actors, implementation strategies and approaches that can strengthen interdisciplinarity in 
Ecohydraulics. Based on an online questionnaire, our investigation first re-examined and updated Wilkes et al. (2016) findings. We then held a follow-up workshop involving ECRs and established careers in Ecohydraulics at a pre-conference event for the 12th International Symposium on Ecohydraulics (ISE) in Tokyo, 2018. This paper resumes a critical reflection on where the Ecohydraulics community stands today and where efforts need to be invested in the long-term to consolidate its inherent interdisciplinarity.

\section{Pre-workshop questionnaire}

\subsection{Questions and targeted respondents}

To assess the current status of the challenges, opportunities, and future directions in Ecohydraulics identified during the first Early Career on Ecohydraulics Network (ECoENet) workshop in 2016 (Wilkes et al., 2016), we created an anonymous online questionnaire that revisited them. The questionnaire was composed of 14 questions divided into four sections: (i) respondents' professional experience, (ii) challenges and opportunities, (iii) future directions, and (iv) respondents' personal background. Four multiple-choice questions focused on the professional experience of the respondents, including defining their career stage, background training, and identifying macro-topics of their core research. Five questions addressed the set of challenges and opportunities in Ecohydraulics by evaluating the respondent's level of agreement or disagreement with specific questions. One question addressed the future directions in Ecohydraulics by asking respondents to identify potential actions that could help advance the discipline. The last four questions helped portray the personal background of the respondents: current geographical location, gender, age, and whether the respondents had children (see full questionnaire in Appendix 1).

The online questionnaire was distributed on $27^{\text {th }}$ July 2018 through several Ecohydraulics communityrelated email lists, soliciting participation from approximately 300 people. Respondents were given a week to return questionnaires to ensure that results were analysed before the ISE 2018 workshop in Tokyo, which was held in August 2018. A total of 103 participants responded to the questionnaire. The highest response rate came from male participants (61\%), between 25 and 45 years old (63\%), with a current research position in Europe (61\%), either in a temporary research position or as a PhD candidate (50\%). Most respondents were in engineering (39\%), followed by the biological sciences 
151 (29\%, including ecology). The current area of research was a split between physical habitat, flow, fish responses, hydrology, and hydraulic modelling (67\%; Figure 1).

\subsection{Summary of challenges, opportunities, and future directions}

Results from the questionnaire confirmed that the challenges, opportunities, and future directions in Ecohydraulics identified by Wilkes et al. (2016) are still relevant for ECRs. Insights from respondents went beyond the early career community and emphasised how interdisciplinarity in Ecohydraulics was viewed as both a challenge, opportunity and a future direction. While challenges and opportunities were well defined and further discussed by the respondents; future directions were more difficult to characterise, particularly regarding specific actions needed to strengthen interdisciplinarity within Ecohydraulics.

A preliminary analysis of the responses identified four main focus areas, which were later used to structure the discussions at the subsequent workshop. They included: Community Building (CB), Scientific Advancement (SA), Links to the Real World (LRW), and Education and Training (ET). Funding was considered an intersecting topic across the four focus areas, given that several recurrent challenges and opportunities centred around funding sources, and it was also deemed necessary to achieving future endeavours (Figure 2).

Newly identified challenges for Community Building (CB) emphasised persistent disciplinary separatism between 'eco' and 'hydraulics', the lack of a collective community vision for the future, and the absence of a common platform for networking. Respondents identified conferences as places for community growth and building a collective vision, ultimately creating an opportunity for interdisciplinary research in Ecohydraulics internationally (Figure 2).

173 Challenges listed for Scientific Advancement (SA) included: the lack of basic Ecohydraulics concepts 174 and paradigms, the difficulty scaling-up integrative research for a complex global context, and the 175 difficulties of developing interdisciplinary concepts without compromising the quality of the research. 176 By promoting interdisciplinary collaborations, respondents agreed that knowledge in Ecohydraulics 177 might extend beyond current 'eco' and 'hydraulics' core topics.

178 Harnessing technological advances and promoting scientific applications to overcome technological shortcomings were identified as both a new challenge and solution that relate to the focus area Links 
to Real World (LRW). In terms of Education and Training (ET), the trade-off between single-focus specialised training vs all-in-one interdisciplinary degrees was seen as a key challenge that, in turn, can impact both professional and personal development. The participants perceived the Ecohydraulics field of research as an excellent framework to allow specialised education in a core discipline while maintaining broader connections among them (Figure 2).

\section{ISE 2018 workshop}

\subsection{Organisation and participation}

The workshop "Interdisciplinarity in Ecohydraulics: an early career perspective" was held on August $19-20,2018$, prior to the $12^{\text {th }}$ International Symposium on Ecohydraulics in Tokyo in the form of a preconference event for ECRs and involving established academics. The workshop set out to identify key actions, actors, implementation strategies, and approaches that may help strengthen interdisciplinarity in Ecohydraulics. The challenges and opportunities summarised in the online questionnaire (Section 2.2) provided the framework for structuring the workshop.

The workshop registered 63 participants with affiliations in Asia (38\%), Europe (37\%), Oceania (13\%), and North America (13\%). Just above half of those registered were male (52\%), PhD candidates or temporary researchers $(51 \%)$, and with a background in engineering $(58 \%$, Figure 1$)$.

\subsection{Workshop sessions}

The workshop was structured in four sessions: keynote introduction and discussion sessions during the first day and a synthesis session and prioritisation exercise on the second day. The scope, the methods, and the outcomes for each session are briefly summarised below.

\section{Keynote introduction}

Four keynote speakers were invited to offer a personal perspective of their career experiences as they relate to interdisciplinarity in Ecohydraulics and engage ECRs to provide their own insights into the

204 field of research at the short Q\&A discussion session. Different criteria were adopted in selecting the speakers: (i) ensure equal gender representation, (ii) representative career stages, and (iii) different 
disciplinary backgrounds, including engineering, ecology, and social sciences. Each presenter contributed their story and experiences of interdisciplinary training and associated challenges. Overall, presentations highlighted a variety of career paths and life experiences that made each interdisciplinarity story unique. The diversity of pathways underscores the challenge and opportunity of mindfully creating interdisciplinary educational programs and cross-national engagement activities that give students practice in interdisciplinary engagement.

\section{Discussion session}

214 The discussion session aimed to identify and structure a series of actions, aligned with the four focus 215 areas that emerged from the questionnaire: Community Building (CB), Scientific Advancement (SA), 216 Links to the Real World (LRW), and Education and Training (ET) (Section 2.2). Participants were also 217 asked to assess whether the future directions identified in the questionnaire were appropriate. 218 Round-table discussions of seven groups were conducted in a manner consistent with the Open Space 219 Technology principles (Owen, 2008), with keynotes acting as discussion facilitators and reporters. In 220 particular, discussion groups were neither assigned a specific focus area nor held to a specific time 221 schedule by the facilitators. To help focus the discussion into a series of actions, we provided a 222 template, where groups were asked to allocate responsibility (Who are the actors?) and identify an 223 approach (What are the implementation strategies and approaches?) to realise identified actions. 224 Answers from each group were later discussed in a plenary session at the end of day one. A summary 225 list of 20 actions was defined, organised by focus areas, and linked to the identified key future directions (Figure 2).

\section{Synthesis session}

The synthesis session opened day two of the workshop, and it was organised as a plenary session. Three synthesis keynote speakers with long-standing roles in the Ecohydraulics community led the opening of the meeting. The synthesis speakers had helped facilitate the previous discussion session and had been asked to synthesise the outcomes for the final prioritisation exercise. scientific community and specific forums, as well as create opportunities to interact with fellow early 
career and established scientists. The synthesis session also verified and consolidated the list of the 20 actions created the day prior and added additional viewpoints from workshop participants.

239 In the final session of the workshop, each participant was asked to vote for their top three key actions 240 from the final consolidated list. The outcomes of the exercise illustrated that although actions focused 241 on Community Building (CB) were prioritised, all other focus areas were deemed similarly important 242 to help increase interdisciplinarity in Ecohydraulics (Figure 3). In terms of specific key actions, 243 promoting one-on-one ECRs-mentor connections (CB), encouraging academic-industry internships 244 (LRW), and the creation of an Ecohydraulics glossary of terms (SA) were the three most voted actions. 245 They were closely followed by actions, such as workshops on disciplinary comparisons (SA), ECoENet's 246 outreach (CB), optimal interdisciplinary training approaches (ET), and the addition of hands-on 247 summer courses in standard University degrees (sUDs), also under the ET focus area(Figure 3).

In regard to the actors, the responsibility for implementing these actions generally lied within ECRs and, in some cases, ECoENet. However, established academics, University departments, and the Ecohydraulics Leadership Team (ELT) were also held responsible for enacting some of the key actions (Table 1). To achieve the listed actions, approaches like targeted workshops, interdisciplinary short courses, and creating new materials (e.g. newsletters, mentorship platforms, and a consolidated Ecohydraulics community mailing list etc.) were proposed.

Concerning the implementation approaches, the ECoENet platform and network were considered to be the best Community Building approach for promoting one-on-one connections between ECRs and mentors. By creating a database of both active mentors and ECRs members, mentors and mentees can be matched based on research areas of interest. Academic-industry internships were thought to be the purview of University departments and ELTs, linking fundamental research to Real World (LRW) contexts by establishing an online registry of contacts. In order to support Scientific Advancement (SA), ECoENet, ECRs, and the ELT were thought to be collectively responsible for creating an Ecohydraulics glossary and linkages among core disciplines. With respect to Education and Training (ET), developing optimal interdisciplinary training approaches and guidelines were deemed the most important, despite appearing only in the $6^{\text {th }}$ position from the prioritisation exercise. Specific 
summer schools by established academics with a teaching focus, and the use and dissemination of interdisciplinary textbooks that cover varied core disciplines within Ecohydraulics (Table 1).

\section{Representativeness of the study}

268 Both the pre-workshop questionnaire and the workshop had high participation relative to the total 269 number of attendants in the 2018 ISE symposium. This fact suggests that the issues raised in both 270 events were likely important to ECRs and the broader Ecohydraulics community. While the crossover between questionnaire and workshop participants was low, the demographics in terms of career stage and background were aligned, which validated the use of the workshop as a continuation of the questionnaire. The low crossover was likely caused by the geographical location of ISE 2018, promoting high participation from Asia. In contrast, the questionnaire sought participants from a consolidated email list issued for ISE 2014 and ISE 2016 symposiums, with high involvement of Europe and Oceania. Although we observed a close gender balance in both exercises, the low participation of scientists with social sciences backgrounds and the lack of participation from Latin American and

278 African countries are still unresolved issues preventing a broader representation within Ecohydraulics

279 (Wilkes et al., 2016), and could be considered a potential limitation of this study.

\section{Discussion}

281 Following the reassessment of key challenges, opportunities, and future directions in Ecohydraulics 282 via the online questionnaire, we identified four key focus areas (Community Building, Scientific 283 Advancement, Links to the Real World, and Education and Training), where support is needed to 284 strengthen interdisciplinarity within Ecohydraulics. All four focus areas and associated actions 285 emerged in a prioritisation exercise during the ISE 2018 workshop, suggesting that efforts are required 286 across the board to reach interdisciplinarity within Ecohydraulics. The list of prioritised actions 287 considered various approaches to engage the community towards specific goals and should help 288 improve long-term interdisciplinarity in Ecohydraulics. Below, we discuss the top prioritised actions in 289 the context of each of the four focus areas (in ascending order of perceived priority). 
Actions in Education and Training were not at the top of the priority list for the majority of participants in the workshop, suggesting that despite ECRs may have felt it an important gap in Ecohydraulics (see Wilkes et al., 2016), they are unempowered to drive the change. Interdisciplinary collaborations have the greatest chance of success when ECRs are able to cultivate their own discipline based on academic interests, but also to look beyond it. The so-called T-shaped researchers have ideally developed breadth and depth during their disciplinary training (see Brown et al., 2016). However, ECRs and students in Ecohydraulics are faced with a lack of interdisciplinary academic departments devoted to the field of research, as well as specialised courses bridging diverse departments. Such institutional barriers force students to choose among various courses offered across several disciplines and departments vs mastering the fundamentals within a specific discipline. For ECRs, such barriers mean that interdisciplinary career development and collaboration are not readily available. As a result, students and ECRs are prevented from cultivating both breadth and depth in their chosen field of research (e.g. jack of all trades, master of none).

305

Another major challenge centres around educators expected to design and deliver true interdisciplinary academic courses (action ET1, priority \#6). Without consolidated Ecohydraulics textbooks (action ET3, priority \#13), compounded by the logistical and institutional constraints of having an interdisciplinary course, it is no wonder that Ecohydraulics has yet to reach the levels of a recognised academic discipline. The development of truly interdisciplinary training approaches and guidelines can only be achieved as a collaboration among several established academics from varied backgrounds, representing the core disciplines in Ecohydraulics, and the full support of University departments interested to contribute to the emerging field of research. Despite some efforts made to integrate Ecohydraulics at the departmental and University level structures, academic departments need to initiate interdisciplinarity through the support of specific actions.

317 Ecohydraulics research must convert fundamental and applied research findings into practical tools 318 that can be easily used and applied by practitioners and governmental agencies. Engaging policy and 319 industry in the design of novel techniques and methods to further the Ecohydraulics toolbox should meaningfully contribute to the future success of Ecohydraulics as an established interdisciplinary field of research and positively impact society. 
Increased engagement with industry from early ECRs via academic-industry internships (action LRW1, priority \#2) has the potential to bridge Ecohydraulics research with the real-world outcomes and implementation of tools. Institutions affiliated with university departments must take the lead to foster stronger relationships with industry and governmental agencies and support ECRs' career development. This investment should positively feedback to the field of research in Ecohydraulics and society in general.

\section{Scientific Advancement (SA)}

330

Despite the many important advances in Ecohydraulics applications, there has not been a parallel evolution in the research theory independent of the core disciplines. Such applications have produced largely empirical research and models, often with limited applicability beyond the conditions in which they were developed. A significant challenge is to find ways to advance Ecohydraulics theory and develop research programs to test these theories without retreating to the traditional reductionist approaches of the parent disciplines. This can be achieved by developing a collective future vision as a research community and a set of shared concepts and paradigms (Nestler et al., 2016).

The creation of an Ecohydraulics glossary of terms (action SA1, priority \#3) was seen as a good starting point to ensure that all the disciplines related to Ecohydraulics have a common vocabulary and engage the diverse disciplines within Ecohydraulics in a conversation on the use of terms. This would be a first step towards consolidating shared concepts and paradigms, and undertaking integrative

341 interdisciplinary research without compromising the advancement of each individual discipline.

342 Another action suggested the organisation of workshops to brainstorm on Ecohydraulics 343 fundamentals (action SA5, priority \#18). The low priority given to this action perhaps reflects that the 344 basic common language is not yet been developed, and ECRs are not ready to engage in such conversations.

While a renewed focus on advancing Ecohydraulics theory is an opportunity, the Ecohydraulics community will have to overcome significant funding challenges. Interdisciplinary research requires collaborations among research groups and across traditional disciplines. Collaborative projects require substantial resources to support long-term experimental programs that achieve significant advances because of the complex interdisciplinary nature of Ecohydraulics. Establishing such programs requires 
substantial funding from different stakeholders, which is often lacking in a sector where funding agencies are looking for quick solutions to pressing local management concerns, reflecting a disconnect between Ecohydraulics research goals set out by academics and funding agencies expectations. The value of investing in long-term theoretical Ecohydraulics research in the grand scheme of improving aquatic ecosystems management needs to be better articulated to national and international funding agencies.

\section{Community Building (CB)}

360

361

362

363

364

365

366

367

368

369

370

371

372

373

374

375

376

377

378

379
The Ecohydraulics community is mostly united and engaged through the biennial ISE symposium (Casas-Mulet et al., 2016). While it initially started as an informal support group of researchers, it has now grown into a mindful, strategic organisation of substantial size, influence, and recognition. This leads to the logical question: is Ecohydraulics at the point where it merits institutional recognition? An institutionalisation of Ecohydraulics would mean the development of a shared mission for both the field of research and the community. The establishment of formal organisational structures within Ecohydraulics is critical to engaging people, allows the community to grow, and empowers community volunteers to support more specific actions. While the Ecohydraulics community can learn from written experiences of scientific institutionalisation (e.g. Gaëta et al., 2017), its implementation still poses a challenge, and its success will depend on current and future ELTs.

Engaging researchers from all career stages is crucial to building community. Scientific leaders at the peak of their careers should lead the establishment of such formal structures, as they are in the position to reflect on the overall vision of Ecohydraulics and are most likely training a critical mass of students and postdoctoral researchers on interdisciplinary research projects. The participation of ECRs in such formal structures is key. Still, their involvement must reflect their need for building their repertoire of skills with different basic and applied research challenges and establishing their careers in centres of excellence. The development of a mentorship program (action CB1, priority \#1) has the potential to engage individuals at different career stages in Ecohydraulics by contributing to the field of research through collaboration mentorship, advice, and networking among peers, linking disciplines together and ultimately driving Ecohydraulics towards a more formalised field of research.

Another key action to help with $\mathrm{CB}$ is the creation of an inclusive Research Forum (action CB3, priority \#9), including individuals from diverse geographic locations, disciplinary backgrounds and career stages. Current and developing online platforms (e.g. Ecohydraulics website, ECoENet social media 
platforms) are a good start, however, the Ecohydraulics community and ELT at large should be responsible for actively engaging researchers from diverse core disciplines and nurturing a constructive dialogue among them. Inspiring students, ECRs, and established research leaders to collectively build the Ecohydraulics community, should also foster growth through learning and creative exchanges, facilitating the evolution of the discipline beyond the $C B$ actions currently identified.

According to Schummer (2004), there are two components to the establishment of a field of interdisciplinary research: (i) the knowledge base (concepts and beliefs, methods, values), and (ii) the social aspects (ways in which the body of knowledge is communicated, shared and taught). It appears that the majority of actions identified in this paper are on the social aspects relevant to Ecohydraulics (Community Building, Links to the Real World, and Education and Training) vs only one on the knowledge base (Scientific Advancement). Despite a clear lack of shared concepts and paradigms in Ecohydraulics, the dominant engineering perspective provides a well-established link with research applications, providing the foundation for a consensus on the knowledge base. However, a community vision designed to bring researchers rooted in different disciplines together (Schummer, 2004) remains the key challenge. Ecohydraulics should, thus, invest most of their efforts and resources into developing the above-mentioned social aspects. The question remains whether new institutional structures within Ecohydraulics will enable more integration between the disparate disciplines, particularly those with the social sciences (Porter and Rafols, 2009), where the gap is more apparent.

\section{Conclusion}

This study presents a collective effort amongst established and early career scientists with different disciplinary backgrounds to identify, discuss, and prioritise specific actions to support the development of true interdisciplinarity within Ecohydraulics. A total of 20 actions involving a range of actors, implementation strategies and approaches within Ecohydraulics were identified depicting a network of players, from individuals at different career stages, to institutions, working together across all focus areas towards achieving true interdisciplinarity. Outcomes from the exercise helped evaluate

411 the current state of the Ecohydraulics community and provided a roadmap for long-term investment 412 of efforts and resources to consolidate interdisciplinarity. The list of prioritised actions in this paper 
413 should, therefore, be considered as mechanisms to engage the community towards specific goals

414 leading to increased interdisciplinarity. While ECRs have taken the lead to create this roadmap, its 415 implementation is the joint responsibility of more established career scientists, ECRs, and institutions.

416 This paper is a conversation starter for all of those within the Ecohydraulics community. A continued

417 revision of the implementation strategies and approaches to strengthen interdisciplinarity will be 418 needed to tackle global issues in freshwater systems in the future.

419

\section{Acknowledgements}

421 The questionnaire and the workshop were designed and conducted by the Early Career on

422 Ecohydraulics Network (ECoENet). The workshop also received logistic support by the ISE Local

423 Organising Committee. ECoENet and the authors would like to especially thank Dr Shinji Fukuda for

424 his incredible help from beginning to end. We would also like to thank Kurita Water and

425 Environment Foundation (http://www.kwef.or.jp/index.html) for kindly providing financial support

426 to the event. The authors are grateful to key long-standing Ecohydraulics members Atle Harby,

427 Thomas Hardy, and Francisco Martinez-Capel, who supported the workshop and contributed to its

428 success with their insights. Last but not least, we thank all questionnaire respondents and workshop

429 participants for openly sharing their views on Ecohydraulics and early-stage research.

430

431 Disclosure statement

432 No potential conflict of interest was reported by the authors.

433

434 ORCID

Roser Casas-Mulet http://orcid.org/0000-0002-7139-8859

436 Davide Vanzo http://orcid.org/0000-0002-2033-9197 
Ana Adeva-Bustos https://orcid.org/0000-0001-7655-784X

438 Camille Macnaughton https://orcid.org/0000-0002-9523-4947

439 Michael Stewardson https://orcid.org/0000-0003-1356-0472

440 Gregory Pasternack https://orcid.org/0000-0002-1977-4175

441 Eva Enders http://orcid.org/0000-0003-2103-0359

442 Fiona Dyer https://orcid.org/0000-0003-4658-9247

\section{References}

445

446

447

448

449

450

451

452

453

454

455

456

457

458

459

460

461

462

463

464

465

466

467

468

469

470

471

472

473

Bina, O., 2017. 1st INTREPID Policy Brief: Recommendations on Integrating Interdisciplinarity, the Social Sciences and the Humanities and Responsible Research and Innovation in EU Research.

Brown, R.R., Deletic, A., Wong, T.H.F., 2016. Interdisciplinarity: How to catalyse collaboration 525, 315-317. https://doi.org/10.1038/525315a

Casas-Mulet, R., King, E., Hoogeveen, D., Duong, L., Lakhanpal, G., Baldwin, T., Stewardson, M.J., Webb, J.A., 2016. Two decades of ecohydraulics: trends of an emerging interdiscipline. J. Ecohydraulics 1, 16-30. https://doi.org/10.1080/24705357.2016.1251296

Döll, P., Zhang, J., 2010. Hydrology and Earth System Sciences Impact of climate change on freshwater ecosystems: a global-scale analysis of ecologically relevant river flow alterations. Hydrol. Earth Syst. Sci 14, 783-799. https://doi.org/10.5194/hess-14-783-2010

Dollar, E.S.J., James, C.S., Rogers, K.H., Thoms, M.C., 2007. A framework for interdisciplinary understanding of rivers as ecosystems. Geomorphology 89, 147-162. https://doi.org/https://doi.org/10.1016/j.geomorph.2006.07.022

Engineering Committee on Science, 2004. Facilitating interdisciplinary research.

European Research Advisory Board, 2008. Report of Activities (2001-20017): European Research Advisory Board.

Freeth, R., Caniglia, G., 2020. Learning to collaborate while collaborating: advancing interdisciplinary sustainability research. Sustain. Sci. 15, 247-261. https://doi.org/10.1007/s11625-019-00701-z

Gaëta, B.A., De Las Rivas, J., Horton, P., Meysman, P., Mulder, N., Romano, P., Welch, L., 2017. Ten simple rules for forming a scientific professional society. PLoS Comput. Biol. 13, 1-8. https://doi.org/10.1371/journal.pcbi.1005226

Geist, J., 2011. Integrative freshwater ecology and biodiversity conservation. Ecol. Indic. 11, 15071516. https://doi.org/10.1016/j.ecolind.2011.04.002

Gosselin, M.-P., Ouellet, V., Harby, A., Nestler, J., 2019. Advancing ecohydraulics and ecohydrology by clarifying the role of their component interdisciplines. J. Ecohydraulics 4, 172-187. https://doi.org/10.1080/24705357.2019.1658137

Hannah, D.M., Sadler, J.P., Wood, P.J., 2007. Hydroecology and ecohydrology: a potential route forward? Hydrol. Process. 21, 3385-3390. https://doi.org/10.1002/hyp.6888 
Hicks, C.C., Fitzsimmons, C., Polunin, N.V.C., 2010. Interdisciplinarity in the environmental sciences: Barriers and frontiers. Environ. Conserv. 37, 464-477. https://doi.org/10.1017/S0376892910000822

Huutoniemi, K., Klein, J.T., Bruun, H., Hukkinen, J., 2010. Analyzing interdisciplinarity: Typology and indicators. Res. Policy 39, 79-88. https://doi.org/https://doi.org/10.1016/j.respol.2009.09.011

Kemp, P.S., Katopodis, C., 2016. Introducing the Journal of Ecohydraulics: fundamental and applied research on the road to transdisciplinarity. J. Ecohydraulics 1, 1-4. https://doi.org/10.1080/24705357.2016.1259139

Kumar, S., Zöphel, C., Martius, A., Cabadag, R., Plewnia, F., Pruditsch, N., Sakowski, B.A., Möst, D., 2019. Stronger together-A framework for measuring interdisciplinary understanding. WIREs Energy Environ. 8, e348. https://doi.org/10.1002/wene.348

Lancaster, J., 2018. What is the right scale? Encouraging fruitful engagement for ecology with ecohydraulics. J. Ecohydraulics 3, 63-76. https://doi.org/10.1080/24705357.2018.1535260

Maddock, I., Harby, A., Kemp, P., Wood, P., 2013a. Ecohydraulics: an introduction. Ecohydraulics An Integr. Approach, Ed 1.

Maddock, I., Harby, A., Kemp, P., Wood, P., 2013b. 25 Research Needs, Challenges and the Future of Ecohydraulics Research, in: Ecohydraulics. Wiley Online Library, p. 431.

Maddock, I., Harby, A., Kemp, P., Wood, P.J., 2013c. Ecohydraulics: an integrated approach. John Wiley \& Sons.

Nestler, J.M., Goodwin, R.A., Smith, D.L., Anderson, J.J., 2008. A Mathematical and Conceptual Framework for Ecohydraulics. Hydroecology Ecohydrol., Wiley Online Books. https://doi.org/doi:10.1002/9780470010198.ch12

Nestler, J.M., Stewardson, M.J., Gilvear, D.J., Webb, J.A., Smith, D.L., 2016. Ecohydraulics exemplifies the emerging "paradigm of the interdisciplines." J. Ecohydraulics 1, 5-15. https://doi.org/10.1080/24705357.2016.1229142

Owen, H., 2008. Open Space Technology: A User's Guide, Third Edit. ed. Berrett-Koehler Publishers.

Palmer, M.A., Menninger, H.L., Bernhardt, E., 2010. River restoration, habitat heterogeneity and biodiversity: A failure of theory or practice? Freshw. Biol. 55, 205-222. https://doi.org/10.1111/j.1365-2427.2009.02372.x

Pasternack, G.B., 2019. Natural Fluvial Ecohydraulics, in: Wohl, E. (Ed.), Environmental Science. Oxford University Press, New York. https://doi.org/10.1093/obo/9780199363445-0111

Porter, A.L., Rafols, I., 2009. Is science becoming more interdisciplinary? Measuring and mapping six research fields over time. Scientometrics 81, 719. https://doi.org/10.1007/s11192-008-2197-2

Reid, A.J., Carlson, A.K., Creed, I.F., Eliason, E.J., Gell, P.A., Johnson, P.T.J., Kidd, K.A., MacCormack, T.J., Olden, J.D., Ormerod, S.J., Smol, J.P., Taylor, W.W., Tockner, K., Vermaire, J.C., Dudgeon, D., Cooke, S.J., 2019. Emerging threats and persistent conservation challenges for freshwater biodiversity. Biol. Rev. 94, 849-873. https://doi.org/10.1111/brv.12480

Rice, S.P., Little, S., Wood, P.J., Moir, H.J., Vericat, D., 2010. The relative contributions of ecology and hydraulics to ecohydraulics. River Res. Appl. 26, 363-366. https://doi.org/10.1002/rra.1369

Schummer, J., 2004. Interdisciplinary Issues in Nanoscale Research. Discov. nanoscale 9-20.

Strayer, D.L., Dudgeon, D., 2010. Freshwater biodiversity conservation: recent progress and future challenges. J. North Am. Benthol. Soc. 29, 344-358. https://doi.org/10.1899/08-171.1

Vörösmarty, C.J., McIntyre, P.B., Gessner, M.O., Dudgeon, D., Prusevich, A., Green, P., Glidden, S., 
Bunn, S.E., Sullivan, C.A., Liermann, C.R., Davies, P.M., 2010. Global threats to human water security and river biodiversity. Nature 467, 555-561. https://doi.org/10.1038/nature09440

519 Wilkes, M.A., Neverman, A.J., Casas-Mulet, R., Adeva-Bustos, A., McCluskey, A.H., Ouellet, V., Vanzo, D., Franklin, P.A., Silva, A.T., 2016. Early careers on ecohydraulics: challenges, opportunities and future directions. J. Ecohydraulics 1, 102-107.

522 https://doi.org/10.1080/24705357.2016.1249423

523

524

525 
Table 1. Summary of workshop-identified actions to improve interdisciplinarity in Ecohydraulics, including the responsibility (Actor) of initiating the action and the implementation strategy and approach to undertaking the action.

\begin{tabular}{|c|c|c|c|c|c|}
\hline $\begin{array}{l}\text { Focus } \\
\text { Area }\end{array}$ & Code & Action & $\begin{array}{c}\text { Priority } \\
\#\end{array}$ & Responsibility (Actors) & Implementation strategy and approach \\
\hline \multirow{13}{*}{ 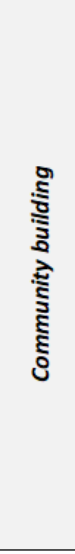 } & CB1 & - Promote one-to-one connections of ECRs with mentors & 1 & ECoENet & $\begin{array}{l}\text { Create of a database of mentors and ECR members research areas to } \\
\text { match interests }\end{array}$ \\
\hline & & & & ELT & Create of an Ecohydraulics community mailing list \\
\hline & CB2 & - Support ECoENet's outreach & 5 & ECRs & Encourage ECoENet's Newsletter subscription \\
\hline & & & & Established academics & Encourage PhD students to support the Network \\
\hline & & & & EcoENet & Creation of information packages \\
\hline & & & & & Promote actions at conferences \\
\hline & CB3 & - Promote the creation of an inclusive Research Forum & 9 & ELT, ECRs & $\begin{array}{l}\text { Join existing platforms, improve them by enabling quality control and } \\
\text { content moderation }\end{array}$ \\
\hline & CB4 & - Create Regional Groups within ECoENet & 10 & ECoENet & Identify common research/career goals with ECRs on a continuous \\
\hline & & & & ECRs & basis \\
\hline & & & & Established academics & Increase trust within the Network \\
\hline & & & & & Encourage PhD students to support the Network \\
\hline & CB5 & - Create multilingual materials & 11 & To be determined & To be determined \\
\hline & CB6 & - Support the establishment of JoE & 15 & To be determined & To be determined \\
\hline \multirow{5}{*}{ 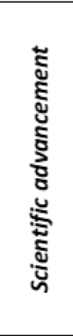 } & SA1 & - Create an Ecohydraulics glossary of terms & 3 & ECRs, EcoENet, ELT & $\begin{array}{l}\text { List and define a database of terms led by motivated individuals, } \\
\text { supported by EcoENet and ELT }\end{array}$ \\
\hline & SA2 & $\begin{array}{l}\text { - Organise hands-on workshops to compare disciplinary } \\
\text { field, lab and analysis approaches }\end{array}$ & 4 & Established academics, ECRs & $\begin{array}{l}\text { Organise sessions embedded in student courses or multi- } \\
\text { departmental activities }\end{array}$ \\
\hline & SA3 & - Organise Wiki writing sessions & 8 & ECRs, ECoENet & $\begin{array}{l}\text { Suggest it as a Pre-ISE workshop topic, or strategic action within } \\
\text { EcoENet }\end{array}$ \\
\hline & SA4 & - Encourage multidisciplinary departmental seminars & 17 & ECRs, Established academics & $\begin{array}{l}\text { Build up multidisciplinary research from existing departmental } \\
\text { activities, and consider include an ice-breaker }\end{array}$ \\
\hline & SA5 & - Organise brainstorming workshops on fundamentals & $18^{*}$ & Established Academics, ECRs & To be determined \\
\hline \multirow{5}{*}{ 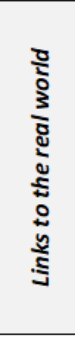 } & LRW1 & - Promote academic-industry internships & 2 & $\begin{array}{l}\text { University Departments } \\
\text { Industry/Agencies } \\
\text { ELT }\end{array}$ & Establish the link and the platform through the ELT \\
\hline & LRW2 & - Encourage research dissemination in layman's terms & 12 & $\begin{array}{l}\text { Journal of Ecohydraulics, } \\
\text { University Departments }\end{array}$ & $\begin{array}{l}\text { Establish a layman's term abstract as a mandatory exercise when } \\
\text { submitting a paper }\end{array}$ \\
\hline & LRW3 & $\begin{array}{l}\text { - Organise hands-on workshops for the creation of } \\
\text { interdisciplinary software }\end{array}$ & 14 & $\begin{array}{l}\text { Industry } \\
\text { University Departments? }\end{array}$ & Target workshops with Industry funding \\
\hline & LRW4 & - Create guidelines for positive interactions with the public & 16 & ELT, General public & Target workshops with ELT funds and involve the general public \\
\hline & LRW5 & - Organise workshops to address targeted real-world issues & $18^{*}$ & To be determined & To be determined \\
\hline \multirow{4}{*}{ 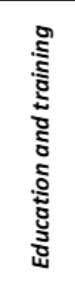 } & ET1 & - Define optimal interdisciplinary training approach & 6 & $\begin{array}{l}\text { Established academics with } \\
\text { teaching focus }\end{array}$ & $\begin{array}{l}\text { Provide the definition based on evidence, expertise, and experience, in } \\
\text { parallel with the improvement of standard University Degrees (sUDs) }\end{array}$ \\
\hline & ET2 & $\begin{array}{l}\text { - Include hands-on summer courses in standard University } \\
\text { Degrees (sUDs) }\end{array}$ & 7 & Established academics, ECRs & $\begin{array}{l}\text { Organise multi-departmental short-courses targeting students from } \\
\text { different majors (from BSc to MSc levels) }\end{array}$ \\
\hline & ET3 & - Produce Ecohydraulics textbooks & 13 & $\begin{array}{l}\text { Established Academics with } \\
\text { teaching focus }\end{array}$ & To be determined but linked to ET1. \\
\hline & ET4 & - Extend sUDs to add other disciplinary subjects & $18^{*}$ & University Departments, ECRs & $\begin{array}{l}\text { Challenge Universities to include interdisciplinary subjects at the } \\
\text { request of ECRs and prospective students }\end{array}$ \\
\hline
\end{tabular}


Geographical location

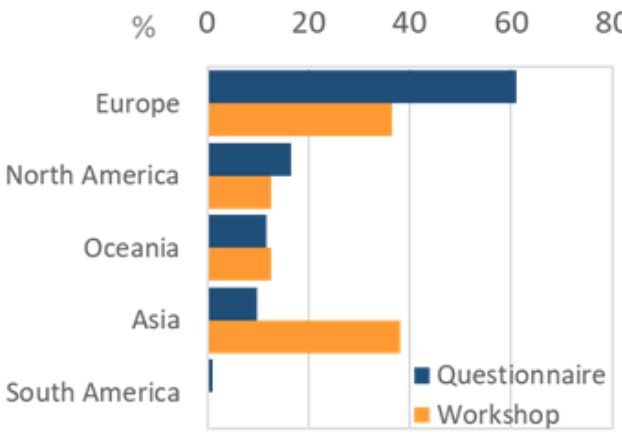

Background

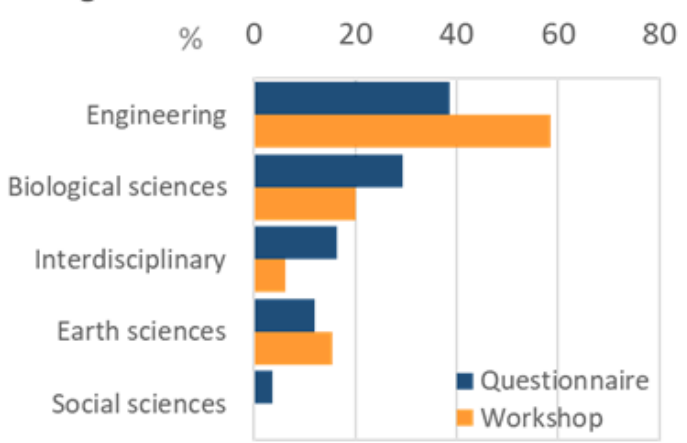

80
Career stage

Temporary researcher

PhD candidate

Tenured academic

Public sector employee

Private sector employee

Permanent researcher

Graduate student

Retired

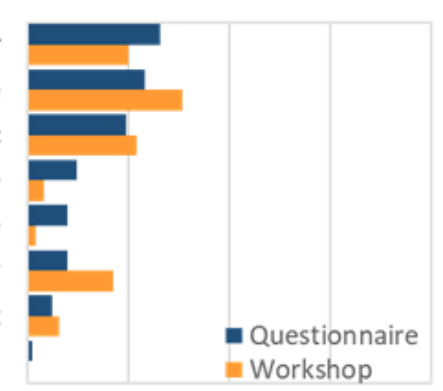

Macrotopics*

$\% \quad 0$

20

40

Physical habitat responses Flow responses

Fish responses Hydrology

Hydraulic modelling

Water quality

Vegetation responses

Invertebrate responses

Social responses

Estuarine responses



Figure 1. Key professional and personal aspects of the questionnaire's respondents and workshop participants including geographical distribution (top left), background by training (top right), career stage (bottom left), and current research focus based on the macrotopics defined in Casas-Mulet et al. 2016* (bottom right, note this information was only provided by the questionnaire's respondents). All values are in percentages. 


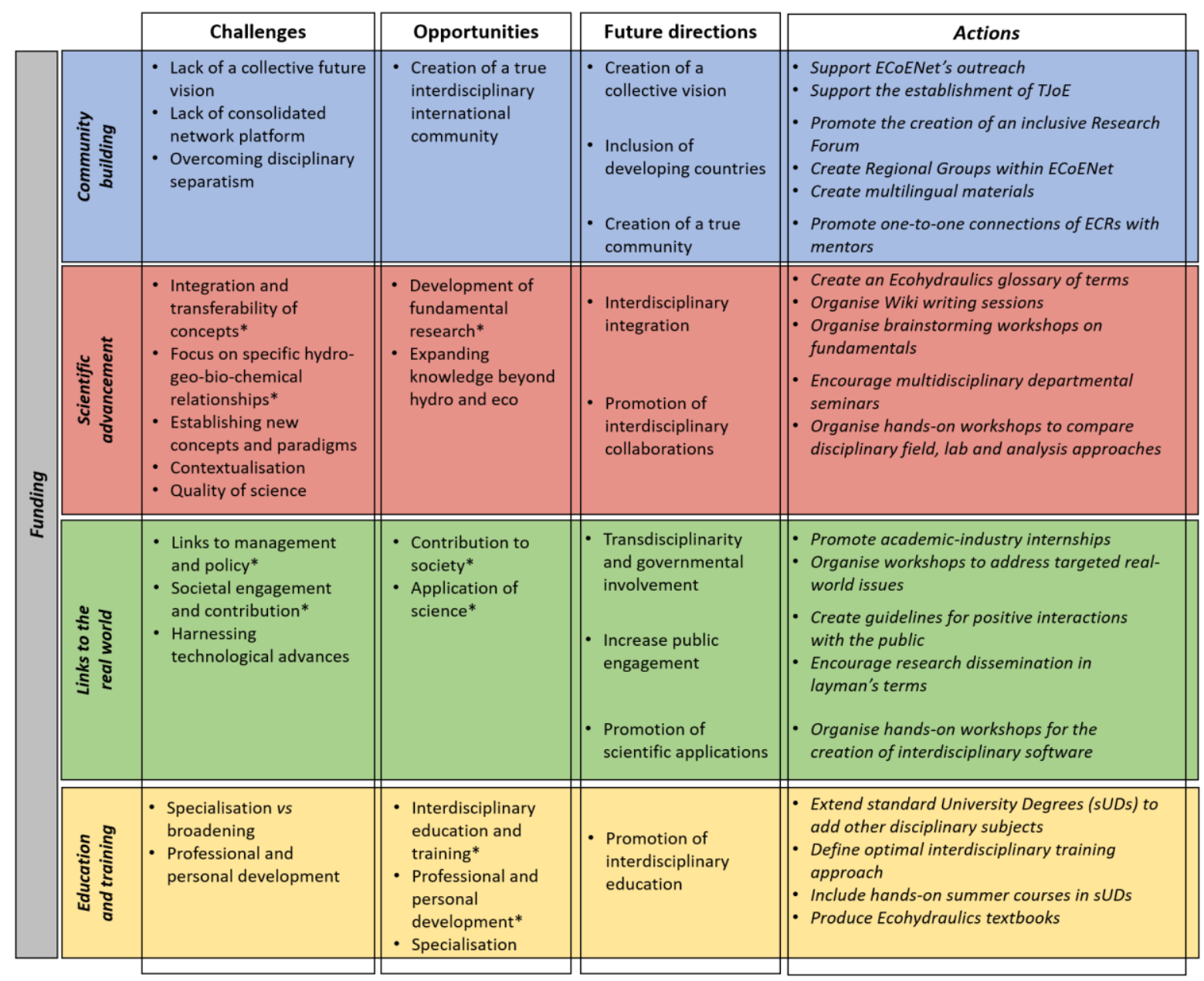

Figure 2. Reviewed challenges and opportunities in Ecohydraulics, and future directions linked to suggested actions. All organised by four identified priority areas "Community building", "Scientific advancement", "Links to the real world" and "Education and training". Note that * indicates items identified in Wilkes et al. 2016. 


\begin{tabular}{|l|l|}
\hline \multicolumn{1}{|c|}{$\%$ Votes } \\
\hline $\begin{array}{l}\text { Community } \\
\text { building }\end{array}$ \\
\hline $\begin{array}{l}\text { Scientific } \\
\text { advancement }\end{array}$ \\
\hline $\begin{array}{l}\text { Links to the } \\
\text { real world }\end{array}$ \\
\hline Education \\
and training
\end{tabular}

$$
40
$$

One-to-one ECR-mentor connections

Academic-industry internships

Ecohydraulics glossary of terms Workshops on disciplinary comparisons ECoENet's outreach

Optimal interdisciplinary training Hands-on summer courses Wiki writing sessions Inclusive Research Forum ECoENet Regional Groups Multilingual materials Research in layman's terms Ecohydraulics textbooks Workshops on interdisciplinary software Establishment of TJOE Guidelines for public interactions Multidisciplinary departmental seminars Additional disciplinary subjects in sUDs Workshops for real-world issues Workshops on fundamentals

$\begin{array}{llll}0 & 3 & 6 & 9\end{array}$

Figure 3. Outcomes of the prioritisation exercise illustrating the percentage of votes received by focus areas (left) and by specific actions (right). 